\title{
Self-reported waist circumference compared with the 'Waist Watcher' tape-measure to identify individuals at increased health risk through intra-abdominal fat accumulation
}

\author{
T. S. Han ${ }^{1,2} *$ and M. E. J. Lean ${ }^{1}$ \\ ${ }^{1}$ University Department of Human Nutrition, Royal Infirmary Queen Elizabeth Building, Alexandra Parade, \\ Glasgow G31 2ER, UK \\ ${ }^{2}$ Wolfson College, University of Cambridge, Cambridge CB3 9BB, UK \\ (Received 29 August 1997 - Revised 22 December 1997 - Accepted 27 January 1998)
}

\begin{abstract}
We evaluated the accuracy of self-reported home-assessed and self-measured waist circumference in 101 men and eighty-three women aged 28-67 years. The main outcome measures were subjects' self-reported and self-measured waist circumference, and self-classification according to the previously defined waist action level 1 (940 $\mathrm{mm}$ in men, $800 \mathrm{~mm}$ in women) and action level $2(1020 \mathrm{~mm}$ in men, $880 \mathrm{~mm}$ in women), and waist circumference measured by the investigator using the 'Waist Watcher' tape-measure, as the reference method. The mean errors (95\% CI limits of agreement) for subjects' self-reported waist circumference (self-reported minus reference; $\mathrm{mm})$ were $-67(95 \% \mathrm{CI}-210,77)$ in men and $-43(95 \% \mathrm{CI}-211,123)$ in women, and for self-measured waist circumference $(\mathrm{mm})$ using the 'Waist Watcher' (selfmeasured minus reference) were $-5(95 \% \mathrm{CI}-62,52)$ in men and $-4(95 \% \mathrm{CI}-50,42)$ in women. The proportions of subjects classified into waist action level 1 or action level 2 by the investigator were used as the reference method. Self-reported waist circumference of men and women respectively would be classified correctly in different categories based on action level 1 with sensitivities of 58.3 and $78.7 \%$, and specificities of 92.5 and $91.7 \%$, and action level 2 with sensitivities of 35.3 and $44.9 \%$, and specificities of 98.5 and $90.7 \%$. Using the 'Waist Watcher' with different colour bands based on the action levels, male and female subjects respectively classified themselves into correct categories according to action level 1 with sensitivities of 100 and $95.7 \%$, and specificities of 95.1 and $97.2 \%$, and according to action level 2 with sensitivities of 97.1 and $100 \%$, and specificities of $100 \%$ for both sexes. Only $2 \%$ of the sample misclassified themselves into the wrong categories according to waist circumference action levels. In conclusion, people tend to underestimate their waist circumference, but the 'Waist Watcher' tape-measure offers advantages over self-reported home-assessed measurement, and may be used as a screening tool for self-classifying the risk of ill health through intra-abdominal fat accumulation.
\end{abstract}

Abdominal fat distribution: Health promotion: Waist circumference

Obesity is increasing by $2-5 \%$ per decade and has now reached an epidemic proportion, affecting more than $15 \%$ in most Western countries (Kuczmarski, 1992; Seidell, 1995). On the basis of current epidemiology and trends, targets set by health authorities to reduce the rising prevalence by the year 2000 will inevitably fail. People in the UK and other urban societies are increasingly suffering from a catalogue of symptoms of obesity and secondary diseases, including tiredness, sweating, breathlessness, back pain, arthritis, menstrual and fertility disorders, cardiovascular disease, non-insulin-dependent diabetes mellitus and several major cancers. These lead to impaired quality of life, depression and premature death. Recent estimates of annual costs for treating obesity are $£ 195$ million in Britain (Office of Health Economics, 1994) and $\$ 70$ billion in the USA (Institute of Medicine, 1995). These estimates, coupled with the lack of public awareness in self-assessment of obesity and a sense of medical impotence in management, urge the development of new strategies. Clinical guidelines for improved medical management are available in several countries (German Society of Obesity Research, 1995; Institute of Medicine, 1995; Scottish Intercollegiate Guidelines Network, 1996).

Health promotion and bathroom scales have hitherto made no impact on the upward trend in overweight and obesity. Given the complex interactions between cosmetic 


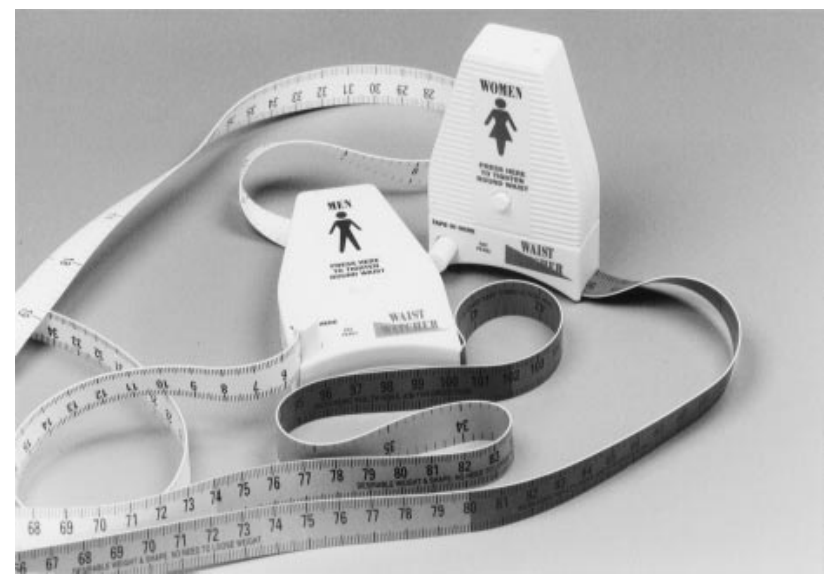

Fig. 1. The 'Waist Watcher' tape-measure. (Further information on the pamphlet containing photographic instructions for measuring waist circumference can be obtained from the authors.)

and health impact of body shape and size, a waist circumference reduction is a rewarding consequence of slimming and has been suggested as a better motivator than weight change (Egger et al. 1995). We have recently proposed the use of waist circumference as a simple method for detecting overweight (BMI) and central fat distribution (waist:hip ratio; Lean et al. 1995), and for identifying people with cardiovascular risk factors (Han et al. 1995, 1996). The values for waist circumference action level $1(940 \mathrm{~mm}$ in men, $800 \mathrm{~mm}$ in women) and action level $2(1020 \mathrm{~mm}$ in men, $880 \mathrm{~mm}$ in women) were identified for health promotion to alert people to increasing health risks (Lean et al. 1995). A 'Waist Watcher' tape-measure (patent pending) was manufactured specifically for the present study based on these action levels (Fig. 1). The present study was designed to evaluate the 'Waist Watcher' tapemeasure in self-measurement and self-classification of waist circumference categories according to the action levels.

\section{Methods}

\section{Subjects}

A subsample of subjects who had participated in the fourth Glasgow MONICA coronary risk factor survey 1 year previously were recalled by letter and telephone. Their selection was based on the predetermined values, according to their previous measured waist circumference and age, available from the fourth Glasgow MONICA database. From these subjects, quota sampling was used in order to assign an approximately equal number to each of the twelve subgroups defined by sex, waist-circumference action levels (below action level 1, between action level 1 and action level 2, and above action level 2), and age (below and above 50 years). Subjects were randomized within each subgroup. One group received general advice about weight management and were given the 'Waist Watcher' tape-measure and guidance in its use (101 men and eighty-three women) to monitor their waist circumference. The other group, serving as controls, did not receive advice or the tape-measure (100 men and seventy-eight women). In the present study, the 101 men and eighty-three women who received the 'Waist
Watcher' were analysed, comparing their baseline selfreported home-assessed, self-measured and self-classified waist circumference according to the action levels with those made by the investigator.

\section{Anthropometry}

Subjects' self-reported home-assessed measurements. Subjects were asked to complete a postal questionnaire about current body weight, height, waist and hip circumferences measured at home by themselves and to bring it with them for a visit to the Department of Human Nutrition, Glasgow Royal Infirmary.

Subjects' self-measured waist circumference using the 'Waist Watcher' tape-measure. Of the 362 subjects recruited, 184 subjects were randomly assigned to receive the 'Waist Watcher' tape-measure to monitor their waist circumference. This group was asked to use the 'Waist Watcher' to measure their waist circumference themselves at the Royal Infirmary. This tape-measure (Fig. 1) was made to help subjects measure their waist circumference easily. The tape is made into a complete loop and fitted firmly around the waist by a spring mechanism, controlled by a push-button. This allows subjects to have their hands free for adjusting the tape. The measurement could be conveniently read by removing the tape from the waist, which was particularly helpful to overweight subjects who found it hard to read bending down. The tape had the conventional numbers in centimetres and inches on each side, and three colour bands separated by action levels: green band to indicate waist circumference below action level 1 ( $<940 \mathrm{~mm}$ in men, $<800 \mathrm{~mm}$ in women); amber band between action level 1 and action level 2 (940$1020 \mathrm{~mm}$ in men, $800-880 \mathrm{~mm}$ in women); and red band above action level $2(\geq 1020 \mathrm{~mm}$ in men, $\geq 880 \mathrm{~mm}$ in women). The meaning of the band colours was explained in the handout Recommendations for Weight Management, which included a set of step-by-step photographic instructions to guide subjects as to how to measure their waist circumference without any assistance from the investigator.

Subjects' waist circumference measured by investigator using 'Waist Watcher' tape-measure. After the subjects had finished measuring their waist circumference using the 'Waist Watcher' tape-measure, they were asked to have their waist circumference measured by the investigator, thus subjects did not know beforehand that their measurement of the waist would be checked. Also, the investigator did not see the subjects' measurement values. Weight, height and hip circumference were also measured according to the World Health Organization (1995) recommendations. The 'Waist Watcher' tape-measure was used by the investigator to measure subjects' circumferences. A 'standard' steel tape (Holtain, Crymych, Dyfed, UK) was also used and gave identical readings.

\section{Analysis}

The accuracy of the subjects' self-reported home-assessed waist circumference, self-measured and self-classification of waist circumference into categories according to the action levels using the 'Waist Watcher' tape-measure, 
Table 1. Characteristics of 101 men and eighty-three women participating in the study*

(Mean values and standard deviations, with ranges)

\begin{tabular}{|c|c|c|c|c|c|c|c|c|}
\hline & \multicolumn{4}{|c|}{ Men } & \multicolumn{4}{|c|}{ Women } \\
\hline \multicolumn{9}{|c|}{ Self-reported, home-assessed measurements $†$} \\
\hline Weight $(\mathrm{kg})$ & 101 & $83 \cdot 7$ & $15 \cdot 1$ & $57 \cdot 2-120 \cdot 8$ & 83 & $70 \cdot 3$ & $13 \cdot 4$ & $50 \cdot 8-108 \cdot 1$ \\
\hline Height (m) & 101 & $1 \cdot 72$ & 0.07 & $1.58-1.90$ & 83 & 1.58 & 0.06 & $1 \cdot 48-1 \cdot 72$ \\
\hline BMI $\left(\mathrm{kg} / \mathrm{m}^{2}\right)$ & 101 & $28 \cdot 1$ & $4 \cdot 5$ & $19 \cdot 8-39 \cdot 7$ & 83 & $28 \cdot 1$ & $5 \cdot 7$ & $18 \cdot 9-45 \cdot 2$ \\
\hline \multicolumn{9}{|c|}{ Waist circumference by subjects using 'Waist Watcher' tape-measure } \\
\hline Waist circumference (mm) & 101 & 981 & 119 & $730-1300$ & 83 & 844 & 130 & $650-1160$ \\
\hline \multicolumn{9}{|l|}{ Measurements by investigator } \\
\hline Weight (kg) & 101 & $84 \cdot 2$ & $15 \cdot 8$ & $53 \cdot 9-126 \cdot 6$ & 83 & $70 \cdot 9$ & $13 \cdot 2$ & $51 \cdot 5-108 \cdot 1$ \\
\hline Height $(\mathrm{m})$ & 101 & $1 \cdot 74$ & 0.07 & $1 \cdot 58-1 \cdot 91$ & 83 & $1 \cdot 61$ & 0.06 & $1 \cdot 47-1 \cdot 72$ \\
\hline
\end{tabular}

${ }^{*}$ For details of subjects and procedures, see p. 82

† Self-reported home-assessed values by subjects were in empirical units and converted to metric units for analysis.

were compared with those made by the investigator using the 'Waist Watcher' tape-measure, which were considered as the reference method. Statistical and graphical presentation based on Bland \& Altman's (1986) methods were used to characterize the biases, errors and $95 \%$ CI limits of agreement of measurements in relation to waist size in each sex group. The proportions of subjects classified into categories of waist-circumference action levels based on their waist circumference measured by the investigator were used as reference group: large waist groups were considered as above action level $1(\geq 940 \mathrm{~mm}$ men, $\geq 800 \mathrm{~mm}$ in women) or above action level $2(\geq 1020 \mathrm{~mm}$ in men and $\geq 880 \mathrm{~mm}$ in women). Sensitivities and specificities (Armitage, 1971) were calculated to assess subjects' ability to classify themselves correctly into categories according to waist-circumference action level 1 or action level 2 . The errors of self-reported hip circumference, weight, height and derived indices, including waist:hip ratio and BMI were also analysed.

\section{Results}

\section{Characteristics of subjects}

Table 1 shows that the mean values for self-reported measurements and those made by the trained investigator were similar. Nearly all subjects reported all the measurements, although only $34 \%$ of the men were able to provide their hip measurement. This suggests that some of the reported values were based on clothes sizes, not measurements.

Table 2 shows that according to the reference measurement made by the investigator, the percentage of subjects with waist circumference below action level 1 was about

Table 2. Proportions of subjects in different categories of waist-circumference action levels identified from measurements made by investigator (reference), from self-reported and from subjects' self-measurements using the 'Waist Watcher' tape-measure*

\begin{tabular}{|c|c|c|c|c|c|c|}
\hline \multirow{2}{*}{$\begin{array}{l}\text { Waist circumference, } \\
\text { based on action levels }\end{array}$} & \multicolumn{2}{|c|}{$\begin{array}{l}\text { By investigator } \\
\text { (reference) }\end{array}$} & \multicolumn{2}{|c|}{ Self-reported } & \multicolumn{2}{|c|}{ Self-measured } \\
\hline & $n$ & $\%$ & $n$ & $\%$ & $n$ & $\%$ \\
\hline \multicolumn{7}{|l|}{ Men $(n$ 101) } \\
\hline$<940 \mathrm{~mm}$ & 41 & $40 \cdot 6$ & 62 & $62 \cdot 0$ & 39 & 38.6 \\
\hline $940-1020 \mathrm{~mm}$ & 26 & $25 \cdot 7$ & 25 & $25 \cdot 0$ & 29 & $28 \cdot 7$ \\
\hline$\geqslant 1020 \mathrm{~mm}$ & 34 & $33 \cdot 7$ & 13 & $13 \cdot 0$ & 33 & $32 \cdot 7$ \\
\hline \multicolumn{7}{|l|}{ Women ( $n$ 83) } \\
\hline$<800 \mathrm{~mm}$ & 36 & $43 \cdot 4$ & 43 & $51 \cdot 8$ & 37 & $44 \cdot 6$ \\
\hline $800-880 \mathrm{~mm}$ & 18 & $21 \cdot 7$ & 22 & $26 \cdot 5$ & 17 & $20 \cdot 5$ \\
\hline$\geqslant 880 \mathrm{~mm}$ & 29 & 34.9 & 18 & $21 \cdot 7$ & 29 & 34.9 \\
\hline
\end{tabular}

${ }^{*}$ For details of subjects and procedures, see pp. 82-83.

† Action level $1940 \mathrm{~mm}$ in men, $800 \mathrm{~mm}$ in women; action level $21020 \mathrm{~mm}$ in men, $880 \mathrm{~mm}$ in women (Lean et al. 1995). 
Table 3. Mean errors and $95 \% \mathrm{Cl}$ limits of agreement, and bias in self-reported and self-measured anthropometry in relation to reference values measured by investigator*

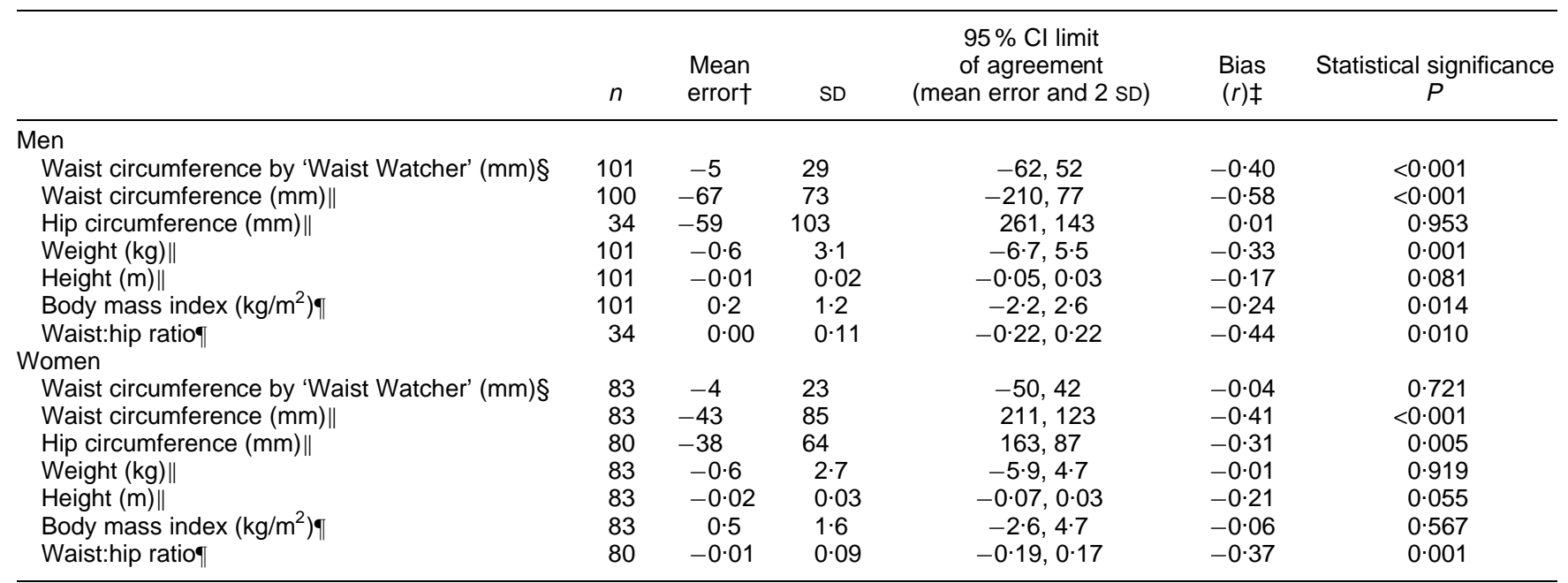

${ }^{*}$ For details of subjects and procedures, see p. 83.

† Self-measured minus reference or self-reported minus reference values (measured by investigator).

$\ddagger$ Correlations between errors of self-reported or self-measured anthropometry with reference values.

$\S$ Errors and bias in self-measured waist circumference by subjects using 'Waist Watcher' tape-measure.

$\|$ Errors and bias in self-reported home-assessed measurements.

IErrors and bias in indices derived from self-reported values.

40 and that above action level 2 was about 35. Subjects tended to under-report their waist circumference, such that there were fewer numbers in the highest (above action level 2) waist circumference category based on self-reported waist measurement. The distribution of subjects in each category based on waist circumference measured by subjects themselves using the 'Waist Watcher' was almost identical to the reference measurement.

\section{Errors and biases in self-reported home-assessed waist circumference in relation to waist size}

Table 3 and Fig. 2(a and b) show that the errors of selfreported home-assessed waist circumference from subjects (self-reported minus reference) were $-67 \mathrm{~mm}(95 \% \mathrm{CI}$ $-210,77)$ in men and $-43 \mathrm{~mm}(95 \% \mathrm{CI}-211,123)$ in women. There was a systematic bias in errors of selfreported waist circumference in men $(r-0.58, P<0.001)$ and in women $(r-0.41, P<0.001)$ of different waist size, i.e. subjects with a smaller waist tended to overestimate and those with a larger waist to underestimate their waist size, compared with the reference values.

\section{Errors and biases in self-measured waist circumference in relation to waist size}

Table 3 and Fig. 3(a and b) show that the errors of waist circumference measured by subjects using 'Waist Watcher' tape-measure (self-measured minus reference) were $-5 \mathrm{~mm}$ $(95 \% \mathrm{CI}-62,52)$ in men and $-4 \mathrm{~mm}(95 \% \mathrm{CI}-50,42)$ in women. There was a systematic bias in errors of selfmeasured waist circumference $(r-0 \cdot 40, P=0 \cdot 01)$ in men of different waist size (Table 3, Fig. 3(a)), i.e. men with a smaller waist tended to obtain higher waist measurements and those with a larger waist tended to obtain lower waist measurements, compared with the reference values. No bias in the errors of self-measured waist circumference was observed $(r 0.04, P=0.72)$ in women of different waist size (Table 3, Fig. 3(b)). The variability (spread) in the errors of self-measured waist circumference was similar throughout the range of waist circumference, i.e. subjects with a larger waist gave the same limits of errors as those with a smaller waist (Fig. 3(a and b)).

\section{Biases in self-reported and self-measured waist circumference in relation to age}

There were no significant systematic biases in the errors of self-reported waist circumference with age in men $(r 0.08$, $P=0.43)$ and in women $(r-0.06, P=0.61)$, or in the errors of self-measured waist circumference with age in men $(r 0.06, P=0.53)$ and in women $(r-0.09, P=0.43)$. In younger men and younger women below 40 years, the variability of errors of self-measured waist circumference was less than that in the older groups.

\section{Sensitivities and specificities in the identification of subjects with a large waist circumference based on self-reported home-assessed and self-measured waist circumference}

In Table 4, subjects in categories of waist-circumference action level 1 or action level 2 identified by the investigator were used as reference. Self-reported waist circumference of men and women respectively would be classified correctly in different categories based on action level 1 with sensitivities of 58.3 and $78.7 \%$, and specificities of 92.5 and $91.7 \%$, and action level 2 with sensitivities of 35.3 and $44.9 \%$, and specificities of 98.5 and $90.7 \%$. With the aid of the 'Waist Watcher' tape-measure and photographic instructions, men and women respectively self-classified 
(a) Men

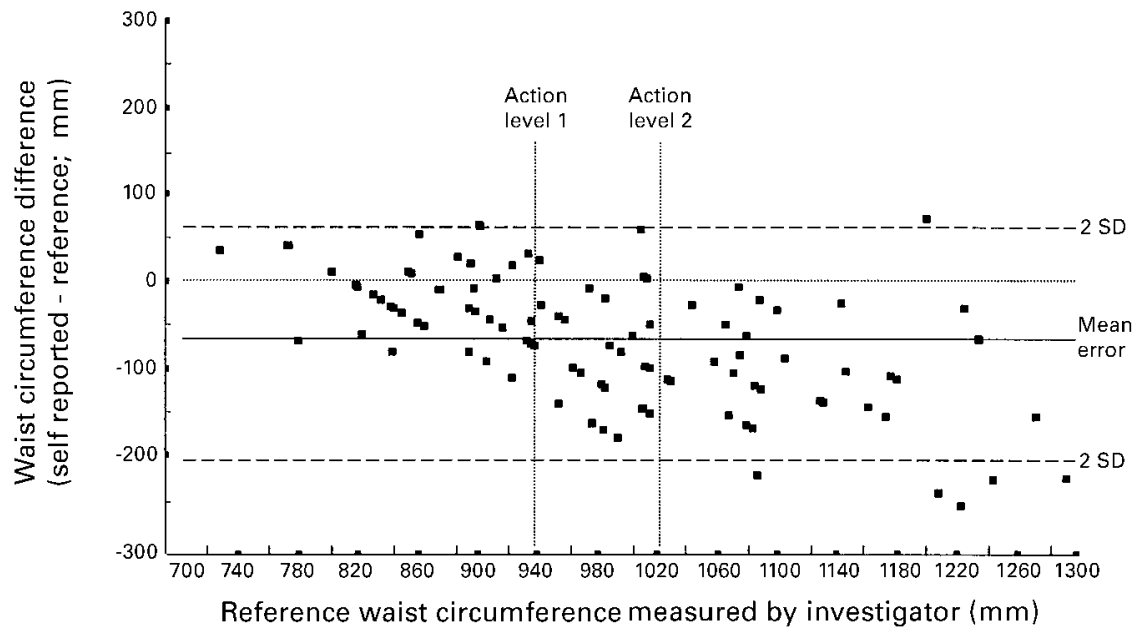

(b) Women

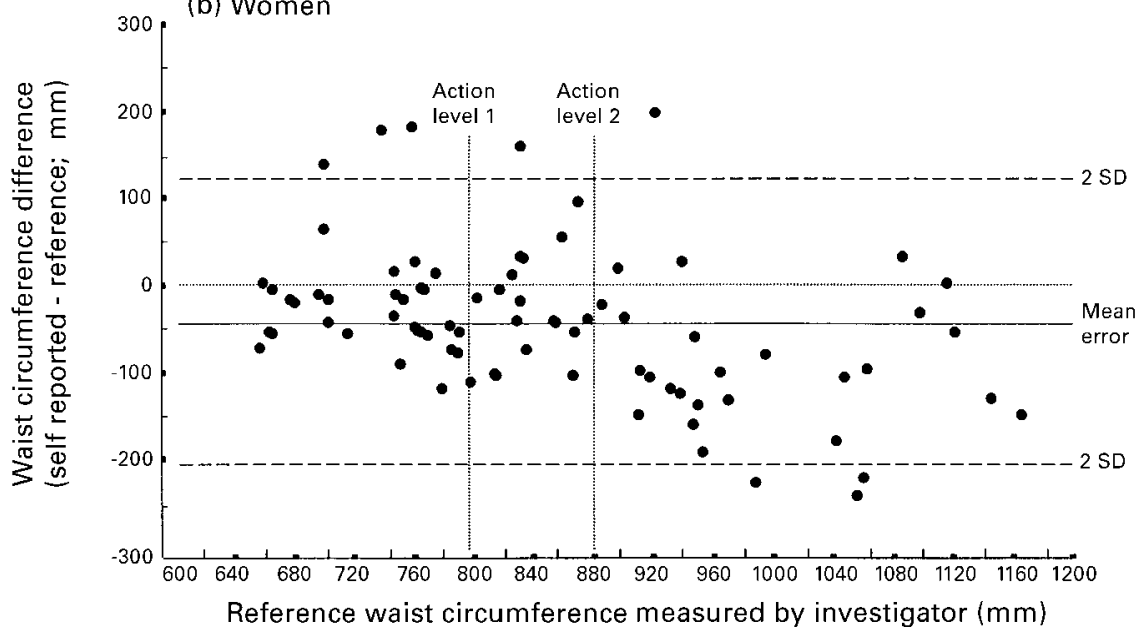

Fig. 2. Plots of errors of self-reported waist circumference (subjects' self-reported values minus reference values measured by investigator) $v$. reference values, in 101 men (a) and eighty-three women (b). (-), Mean error; $(---), 95 \% \mathrm{Cl}$ limits of agreement (2 SD of the mean error). For details of subjects and procedures, see p. 82. (a) $r-0.58, P<0.001$; (b) $r-0.41, P<0.001$.

their waist circumference correctly according to action level 1 with sensitivities of 100 and $95.7 \%$, and specificities of 95.1 and $97.2 \%$, and according to action level 2 with sensitivities of 97.1 and $100 \%$, and specificities of $100 \%$ (both sexes). There were less than $2 \%$ of subjects who misclassified themselves into the wrong categories of waist circumference based on the action levels.

\section{Errors and biases in self-reported measurements of other anthropometric measurements}

Table 3 shows that hip circumference was under-reported by $60 \mathrm{~mm}$ in men and $40 \mathrm{~mm}$ in women. There was no bias in self-reported values in men of different hip sizes $(r 0.01$, $P=0.953)$, and a systematic bias in women $(r-0.32, P=$ $0.005)$, i.e. women with larger hips tended to under-report more than those with smaller hips. The mean errors of waist:hip ratio derived from self-reported waist and hip circumferences were close to zero in both sexes, but there was a significant bias of the errors both in men $(r-0.44$, $P=0.010)$ and in women $(r-0.37, P=0.001)$, thus subjects with a high waist:hip ratio tended to underestimate their waist:hip ratio more than those with a lower waist:hip ratio. Both sexes underestimated their weight by about $0.5 \mathrm{~kg}$, and height by $10 \mathrm{~mm}$ in men and $20 \mathrm{~mm}$ in women. There was a significant bias in errors of weight in men $(r-0.33, P=0.001)$ but not in women $(r-0.01$, $P=0.919$ ), and no systematic bias in the errors of selfreported height for both sexes. The BMI derived from selfreported weight and height was overestimated by $0.2 \mathrm{~kg} / \mathrm{m}^{2}$ by men and $0.5 \mathrm{~kg} / \mathrm{m}^{2}$ by women. Men with a high BMI tended to underestimate their BMI compared with men with a lower BMI $(r-0.24, P=0.014)$. There was no significant bias in the errors of BMI in women. 
(a) Men

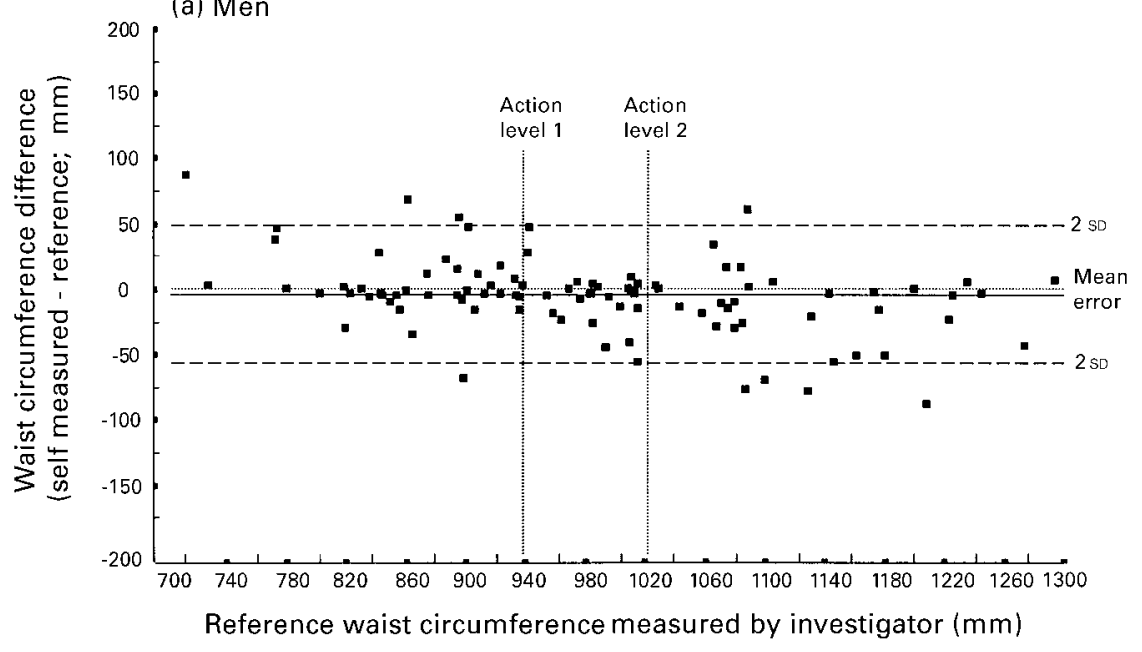

(b) Women

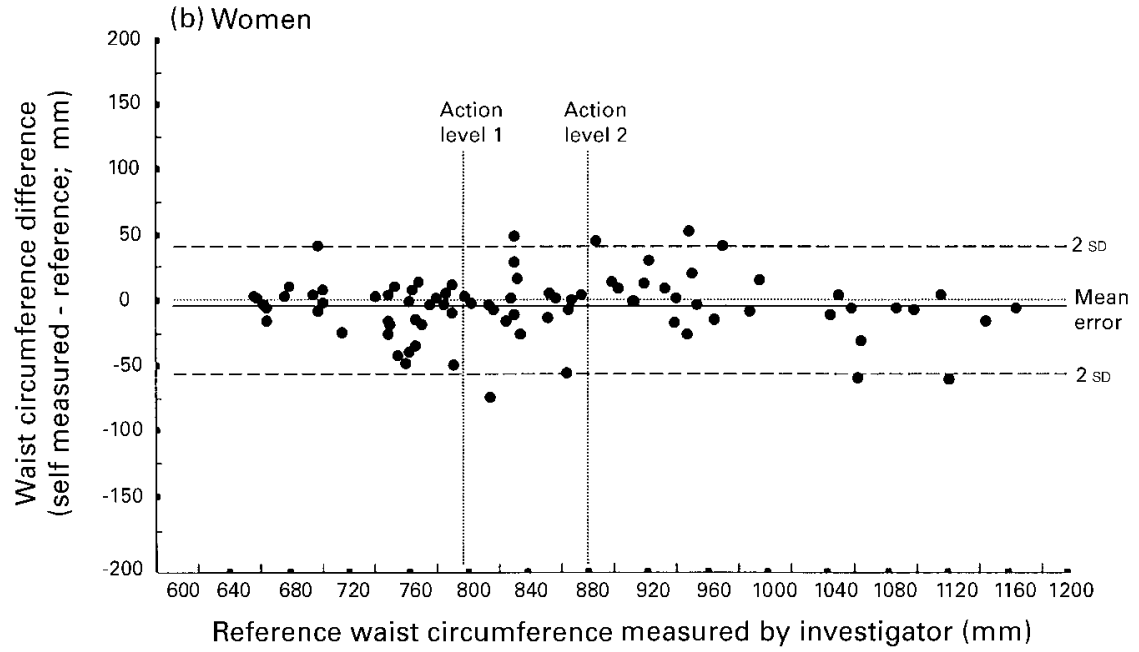

Fig. 3. Plots of errors of self-measured waist circumference using 'Waist Watcher' tapemeasure (subjects' self-measured values minus reference values measured by investigator) $v$. reference values, in 101 men (a) and eighty-three women (b). (-), Mean error; (- - -), $95 \% \mathrm{Cl}$ limits of agreement (2 SD of the mean error). For details of subjects and procedures, see p. 82. (a) $r-0.40, P<0.01$, (b) $r 0.04, P=0.72$.

\section{Discussion}

We have addressed the public health needs, using a single measurement of waist circumference to alert the general public to their risks of ill health, and their need to seek professional help based on the action levels of waist circumference (Lean et al. 1995). Both men and women under-reported their waist circumference, thus the specificities for classification of subjects into the lower categories of waist-circumference action levels were high ( $>90 \%)$, but the sensitivities for identifying those with a larger waist in higher categories of waist-circumference action levels were relatively low $(58-79 \%$ based on action level 1 and $35-45 \%$ based on action level 2). With the aid of the 'Waist Watcher' tape-measure (Fig. 1) and photographic instructions which were designed specifically for the present study to help subjects measure their waist easily, most subjects could identify themselves correctly in different categories of waist circumference according to the action levels with sensitivities and specificities above $95 \%$. Thus, the 'Waist Watcher' tape-measure provides a useful screening tool in health promotion for self-classification of increased health risk through intra-abdominal fat accumulation, which otherwise would be missed from self-reported waist circumference.

Our previous findings indicate clearly that large waist circumference is associated with symptoms of obesity and secondary diseases (Han et al. 1995, 1997a, b; Seidell et al. 1997; Lean et al. 1998) imposing enormous burdens of ill health on health services and society. Waist circumference as an index of adiposity is minimally influenced by height (Han et al. 1997c), although height does have an influence on health which is independent of adiposity. Thus, a single measurement of waist circumference is a valid and simple indicator of ill health. If waist circumference is to be used for health promotion programmes for weight management 
Table 4. Sensitivities and specificities of the identification of subjects into different waist circumference action level categories based on their reported and self-measured waist circumference, using groups classified from measurements made by the investigator as reference*

\begin{tabular}{|c|c|c|c|c|}
\hline & \multicolumn{2}{|c|}{$\begin{array}{c}\text { Self-reported } \dagger \\
\text { waist circumference }\end{array}$} & \multicolumn{2}{|c|}{$\begin{array}{l}\text { Self-measured } \neq \\
\text { waist circumference }\end{array}$} \\
\hline & $\begin{array}{c}\text { Sensitivity } \\
(\%)\end{array}$ & $\begin{array}{l}\text { Specificity } \\
(\%)\end{array}$ & $\begin{array}{c}\text { Sensitivity } \\
(\%)\end{array}$ & $\begin{array}{c}\text { Specificity } \\
(\%)\end{array}$ \\
\hline \multicolumn{5}{|l|}{ Men (n 101) } \\
\hline Action level $1(940 \mathrm{~mm})$ & $58 \cdot 3$ & $92 \cdot 5$ & 100 & $95 \cdot 1$ \\
\hline Action level $2(1020 \mathrm{~mm})$ & $35 \cdot 3$ & $98 \cdot 5$ & $97 \cdot 1$ & 100 \\
\hline \multicolumn{5}{|l|}{ Women ( $n$ 83) } \\
\hline Action level 1 (800 mm) & $78 \cdot 7$ & $91 \cdot 7$ & $95 \cdot 7$ & $97 \cdot 2$ \\
\hline Action level $2(880 \mathrm{~mm})$ & $44 \cdot 9$ & $90 \cdot 7$ & 100 & 100 \\
\hline
\end{tabular}

among the general public, it is essential that the subjects should be able to measure their waist correctly. Some previous studies have found waist circumference measured by trained observers to be reliable (Hall \& Young, 1989; Rimm et al. 1990; Ferrerio et al. 1995). In these studies, conventional tape-measures were used, and these may be problematic for the very obese who cannot see their waist. The 'Waist Watcher' allows a more reliable 'blind' measurement. The present study found that the variability of errors (spread of errors about the mean error) of selfmeasured waist circumference was similar in subjects of different waist size (Fig. 3(a and b)), and younger people were able to measure their waist more accurately than older groups. In the present study, while nearly all subjects were able to report all home-assessed measurements, only $34 \%$ men offered a hip measurement. These results provide further support for the use of a single measurement waist circumference in health promotion directed at the general public.

A recent study on self-reported weight and height in British teenagers (16-17 years) found that shorter and fatter individuals overestimated their height and underestimated their weight, while conversely taller and thinner subjects underestimated their height (Crawley \& Portides, 1995). The agreement between self-reported and measured values for height and weight were within $10 \mathrm{~mm}$ and $1 \mathrm{~kg}$ respectively, but they varied $(95 \% \mathrm{CI})$ by $70 \mathrm{~mm}$ and $7 \mathrm{~kg}$ respectively (Nakatsuka et al. 1995). In the present study, subjects with a large waist size or high waist:hip ratio tended to underestimate their waist circumference and waist:hip ratio. There was no evidence for women with a high body weight or BMI to under-report weight or BMI respectively. These results suggest that subjects were more concerned about their body shape than body mass, such that there was a bias towards reporting a body shape that is less related to abdominal fat accumulation. Including the 100 men and seventy-eight women from the control group for analysis showed an almost identical result in errors and bias of self-reported anthropometric measurements (data not presented).

The present study is part of a larger prospective study.
At baseline, waist size self-reported and self-measured by the subjects using the 'Waist Watcher' tape-measure were compared with that measured by the investigator. Subjects will be recalled to assess the effectiveness of the 'Waist Watcher' tape-measure, used as a motivational tool to prevent weight gain in those with a waist circumference below action level 1, and to encourage weight loss in those with a waist circumference above action level 1. In addition, comparisons between weight and height measured by the investigator and those reported by the subjects, and the influences of body image perception on the differences between self-reported or self-measured anthropometry and assessment by an investigator will be evaluated.

The practical value of this research is that a single measurement of waist circumference can be adopted confidently both by health professionals and the general public as a tool for alerting individuals who need weight management. Health promotion can contribute to weight management by alerting individuals to their level of risk and the need to take action. This implies the need to establish specialized obesity clinics to serve these needs. Individuals with a waist circumference below action level 1 do not need to lose weight but should be aware of potential health risks if their waist exceeds this level. In the range between action level 1 and action level 2, individuals should not further gain weight, but implement lifestyle modification such as increasing physical activity level and some selfweight management. Individuals above action level 2 should be urged to take action and to seek professional help to achieve sustained weight loss. These waist-circumference action levels have already been recognized by epidemiologists in the field of public health (Björntorp, 1997; Carey et al. 1997), and adopted for national health promotion by British Diabetic Association (Walker, 1997), Health Education Board for Scotland (1997), Scottish Intercollegiate Guidelines Network (1996), and the recent National Health and Medical Research Council Working Party on the Prevention of Overweight and Obesity (1997) in Australia. A loss of 50-100 mm in individuals with waist circumferences above the action levels is likely to lead to improved cardiovascular risk factors (Han et al. 1997a). 


\section{Conclusions}

A 'Waist Watcher' tape-measure with photographic instructions offers advantages over self-reported measurement of waist circumference in self-classifying waist size, and provides a useful tool for screening people at increased health risk through intra-abdominal fat accumulation.

\section{Acknowledgements}

We would like to thank Irene Kelly (University Department of Human Nutrition, Glasgow Royal Infirmary) for her important contribution to the data collection for this study, Dr Caroline Morrison (Glasgow arm of WHO MONICA Project, Glasgow Royal Infirmary) for helping with subject recruitment, and Dr James Currall (Department of Computing Service, Glasgow University) for advice on study design and statistical guidance. The study was funded by Department of Human Nutrition Discretionary Funds (TSH), and Rank Foundation and Rank Prize Funds (MEJL). The 'Waist Watcher' tape-measure is being patented by T. S. Han, M. E. J. Lean and I. Murray, Glasgow University.

\section{References}

Armitage P (1971) Statistical Methods in Medical Research. New York: Wiley.

Björntorp P (1997) Obesity. Lancet 350, 423-426.

Bland JM \& Altman DG (1986) Statistical methods for assessing agreement between two methods of clinical measurement. Lancet i, 307-310.

Carey VJ, Walters EE, Colditz GA, Solomon CG, Willett WC, Rosner BA, Speizer FE \& Manson JE (1997) Body fat distribution and risk of non-insulin-dependent diabetes mellitus in women. The nurses' health study. American Journal of Epidemiology 145, 614-619.

Crawley HF \& Portides G (1995) Self-reported versus measured height, weight and body mass index amongst 16-17 year old British teenagers. International Journal of Obesity 19, 579-584.

Egger G, O’Neill M, Bolton A \& Freeman D (1995) Results of an abdominal obesity reduction program for men only: the gutbuster 'waist' loss program. International Journal of Obesity 19, Suppl. 2, 37 Abstr.

Ferrerio M, Carpenter MA \& Chambless LE (1995) Reliability of body fat distribution measurements. The ARIC study baseline cohort results. International Journal of Obesity 19, 449-457.

German Society of Obesity Research (1995) Stellunahme der Deutchen für Adipositasforschung: Richtlinien zur Therapie der Adipositas (Statement of the German Society of Obesity Research: Guidelines for the Treatment of Obesity). Adipositas 9, 6-10.

Hall TR \& Young TB (1989) A validation study of body fat distribution as determined by self-measurement of waist and hip circumferences. International Journal of Obesity 13, 801-807.

Han TS, Richmond P, Avenell A \& Lean MEJ (1997a) Waist circumference reduction and cardiovascular benefits during weight management in women. International Journal of
Obesity 21, 127-134.

Han TS, Schouten JSAG, Lean MEJ \& Seidell JC (1997b) The prevalence of low back pain and associations with body fatness, fat distribution and height. International Journal of Obesity 21, 600-607.

Han TS, Seidell JC, Currall JEP, Morrison CE, Deurenberg P \& Lean MEJ (1997c) The influences of height and age on waist circumference as an index of adiposity. International Journal of Obesity 21, 83-89.

Han TS, van Leer EM, Seidell JC \& Lean MEJ (1995) Waist circumference action levels in the identification of cardiovascular risk factors: prevalence study in a random sample. British Medical Journal 311, 1041-1045.

Han TS, van Leer EM, Seidell JC \& Lean MEJ (1996) Waist circumference as a screening tool for cardiovascular risk factors: evaluation of receiver operating characteristics (ROC). Obesity Research 4, 533-547.

Health Education Board for Scotland (1997) Eating for health. Edinburgh: Health Education Board for Scotland.

Institute of Medicine (1995) Weighing the Options. Criteria for Evaluating Weight Management Programs [PR Thomas, editor]. Washington, DC: National Academic Press.

Kuczmarski RJ (1992) Prevalence of overweight and weight gain in the United States. American Journal of Clinical Nutrition 55, 495S-502S

Lean MEJ, Han TS \& Morrison CE (1995) Waist circumference as a measure for indicating weight management. British Medical Journal 311, 158-161.

Lean MEJ, Han TS \& Seidell JC (1998) Impairment of health and quality of life in people with large waist circumference. Lancet 351, 853-856.

Nakatsuka H, Satoh H, Watanabe T, Ida Y, Nishigouri M \& Ikeda M (1995) The reproducibility of reported height and body weight in repeated questionnaire surveys. International Journal of Obesity 19, 50-56.

National Health and Medical Research Council Working Party on the Prevention of Overweight and Obesity (1997) Acting on Australia's Weight. A Strategic Plan for the Prevention of Overweight and Obesity. Canberra: Australian Government Publishing Service.

Office of Health Economics (1994) Obesity. London: Office of Health Economics.

Rimm EB, Stampfer MJ, Colditz GA, Chute CG, Litin LB \& Willett WC (1990) Validity of self-reported waist and hip circumferences in men and women. Epidemiology 1, 466-473.

Scottish Intercollegiate Guidelines Network (1996) Obesity in Scotland. Integrating Prevention with Weight Management. Edinburgh: Scottish Intercollegiate Guidelines Network.

Seidell JC (1995) Obesity in Europe - scaling an epidemic. International Journal of Obesity 19, Suppl. 3, S1-S4.

Seidell JC, Han TS, Feskens EJM \& Lean MEJ (1997) Narrow hips and broad waist circumferences independently contribute to increased risk of NIDDM. Journal of Internal Medicine 42, 401-406.

Walker L (1997) Going down? Balance, issue no. 156, pp. 41-45. London: British Diabetic Association.

World Health Organization (1995) Physical Status: The Use and Interpretation of Anthropometry. Report of a WHO Expert Committee. Geneva: WHO Technical Report Service. 